\section{Institutes marshal locals to boost African physics}

Two research centres will open their doors in Cape Town, South Africa, this month in a bid to bolster theoretical physics and mathematical sciences across the continent.

A pan-African centre of the existing African Institute for Mathematical Sciences will be launched on 12 May, followed the next day by the National Institute for Theoretical Physics, to be headquartered at the Stellenbosch Institute for Advanced Study.

The two institutes are funded mainly by the South African Department of Science and Technology. The pair will work closely with each other, using mainly local scientific talent to contribute to regional cosmology and astrophysics programmes such as SALT (the Southern Africa Large Telescope) in Sutherland and MeerKAT, a radiotelescope facility under construction in the Karoo desert.

\section{Patent on Mexican yellow beans is reversed}

The US Patent and Trademark office last week overturned a controversial patent on a breed of yellow beans. Opponents of the patent say the bean has been eaten in Latin America for more than a century, raising issues of biopiracy.

The patent was granted in 1999 to Larry Proctor of Delta, Colorado. According to the patent application, Proctor bought yellow beans in Mexico and bred them for two years to grow plants that gave a better harvest and produce beans with a distinctive yellow colour.

Proctor then began charging licensing fees on imports of yellow beans from Mexico, prompting the International Center for Tropical Agriculture, based in Cali, Colombia, to challenge the patent in 2001.

But the battle may continue. Proctor has the option of contesting the decision in federal court, and says he is consulting his lawyer. "Everybody may not be happy with what we're fixing to do now," he said, and declined to comment further.

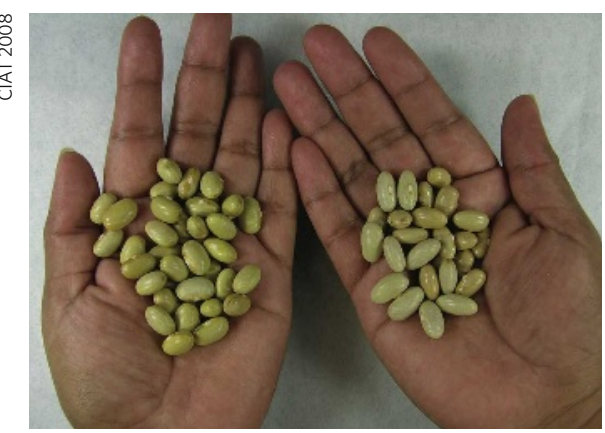

Yellow beans have been freed from patent control.

\title{
Elephant-hunting season opens in South Africa
}

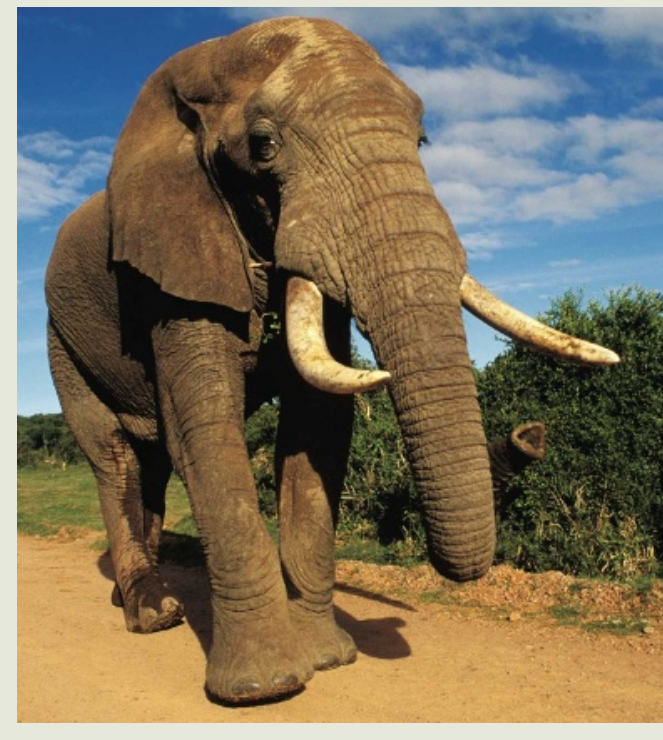

South Africa's 13-year ban on elephant culling was lifted on 1 May to help manage the flourishing population.

The pachyderms (pictured) - once close to being wiped out in many parts of the continent - have more than doubled in number in the country since 1995, generating concerns about vegetation destruction, and threats to people and livelihoods within elephant ranges.

Culling - under strict provisos has been legalized as a last resort, the government asserts. Yet some conservationists have condemned the action, warning that it may encourage ivory poachers and could threaten populations elsewhere.

Alternative ways of curbing elephant numbers include relocating the animals and hormone-based contraception.

\section{Drug firm turns spotlight on basic systems biology}

The pharmaceutical company Pfizer has launched a three-year, US\$14-million systems-biology consortium to improve the understanding of diabetes and obesity.

Systems biology uses computer-intensive data analysis to derive models about specific biological phenomena, and can be used to help study the progression of some diseases. Drug companies have traditionally shied away from it, because it can take a long time to see any financial pay-off. But in March, systems-biology research, funded in part by Merck, identified genes involved in obesity.

In the new Pfizer programme, researchers at the University of California, Santa Barbara, the California Institute of Technology in Pasadena, the Massachusetts Institute of Technology in Cambridge, the University of Massachusetts, and biotechnology company Entelos based in Foster City, California, will examine the regulatory mechanisms involved in insulin signalling in fat cells.

\section{NASA watchdog calls for Orion board suspensions}

NASA's independent investigative arm has called for the suspension of 6 of the 19 members of a board charged with reviewing the agency's programme to replace the space shuttle.

The board members in question are employed by contractors already working on Orion, the shuttle's replacement. This creates a conflict of interest that violates US federal law, the Office of the Inspector General said in a report issued last week.
But NASA officials have said that the board should remain intact and that it is difficult to find completely independent aerospace experts. The inspector-general's office is calling that "nonresponsive". Further action may be taken after 28 May, when NASA's comments on the report are due.

\section{Sacked whistle-blower demands reinstatement}

A researcher who blew the whistle over animal-rights issues at the University of Nevada in Reno went to court last week to try to win his job back after being fired.

Nutrition researcher Hussein Hussein, a tenured professor, was sacked last month by university president Milton Glick, despite a recommendation by a university administrative hearing that he merely be reprimanded or demoted. Four years ago, Hussein reported deficiencies in the care of laboratory animals that led to US\$11,400 in fines against the university. He claims the university sought to fire him in retaliation.

After the administrative hearing, he was cleared of charges of plagiarizing graduate student work, but found to have incorrectly reported on $\$ 377,000$ in grants, thus denying the university overhead costs.

Hussein's lawyer asked a Nevada judge to reinstate him, arguing that he was improperly fired. A spokeswoman says the university acted appropriately, and will vigorously defend its actions.

\section{Correction}

The news story 'Rodent round-up' (Nature 453, $9 ; 2008$ ) incorrectly described the greater whitetoothed shrew as a rodent, when it in fact belongs to the order Soricomorpha. 